\title{
Saving the Javan Rhino
}

\section{Poachers and Food Supply the Two Main Problems}

$\mathbf{T}$ HERE are fewer than 30 Javan rhinos in the world, all in the 300 square-mile Udjung Kulon nature reserve in western Java, and their situation is still critical. This is the verdict of Drs Rudolf and Lotte Schenkel at the end of their seven-month study of the ecology, sociology and behaviour of the Javan rhino. The census of the rhino taken towards the end of their stay showed the population to be down to between 21 and 28 animals, of which, judging from tracks, they estimated that 8 to 11 were adult males, 9 to 12 females or sub-adult males, and 4 to 5 immatures, with no calves under one year old. The small number of young animals and the absence of calves under a year are particularly disturbing. They consider poaching and the shortage of food plants for the rhinos to be two important factors in the situation.

The Schenkels' mission in Udjung Kulon is a continuation of the efforts of IUCN (the International Union for Conservation of Nature), the World Wildlife Fund and the FPS to save the Javan rhino which began in 1964 with Dr and Mrs Lee Talbot's investigation for IUCN. In 1966 Dr Jacques Verschuren went out to start up the scientific research station in the reserve and stayed until April 1967, to be followed by Dr and Mrs Schenkel in May. In 1966 the FPS made its first and largest grant so far from the FPS/WWF Revolving Fund, $£ 3,800$ for a fibre-glass boat that was urgently needed to transport both scientists and guards to and from the reserve. This boat, the Badak (Indonesian for rhino), has been in use since January 1967. The Schenkels' mission is financed by the Swiss National Appeal of the World Wildlife Fund, with earmarked donations raised by the Basel Patronage Committee, formed by Professor Geigy. Money to buy a Land Rover was raised mainly by the Eastbourne Group of WWF. This year the FPS has made a further grant of $£ 830$ from the FPS/WWF Revolving Fund towards the work, which the Schenkels were to resume in August 1968.

\section{Equipment for the Guards}

The Schenkels consider poaching to be the most important reason for the decrease in the rhinos - at least 12 are known to have been killed immediately before the Talbots' visit in 1964 - and one of their first tasks was to reorganise the guard system. This proved to be mainly a financial problem: to give the guards adequate salaries, uniforms, equipment and housing. Thanks to the intervention of General Lindbergh, who was visiting the reserve, it was possible in June 1967 to start equipping the guards as a WWF project in co-operation with the Indonesian authorities. Dr Schenkel also conducted special training courses for them.

The other important factor in the situation say the Schenkels, and one which is hampering the recovery of the rhino population, is a shortage of 


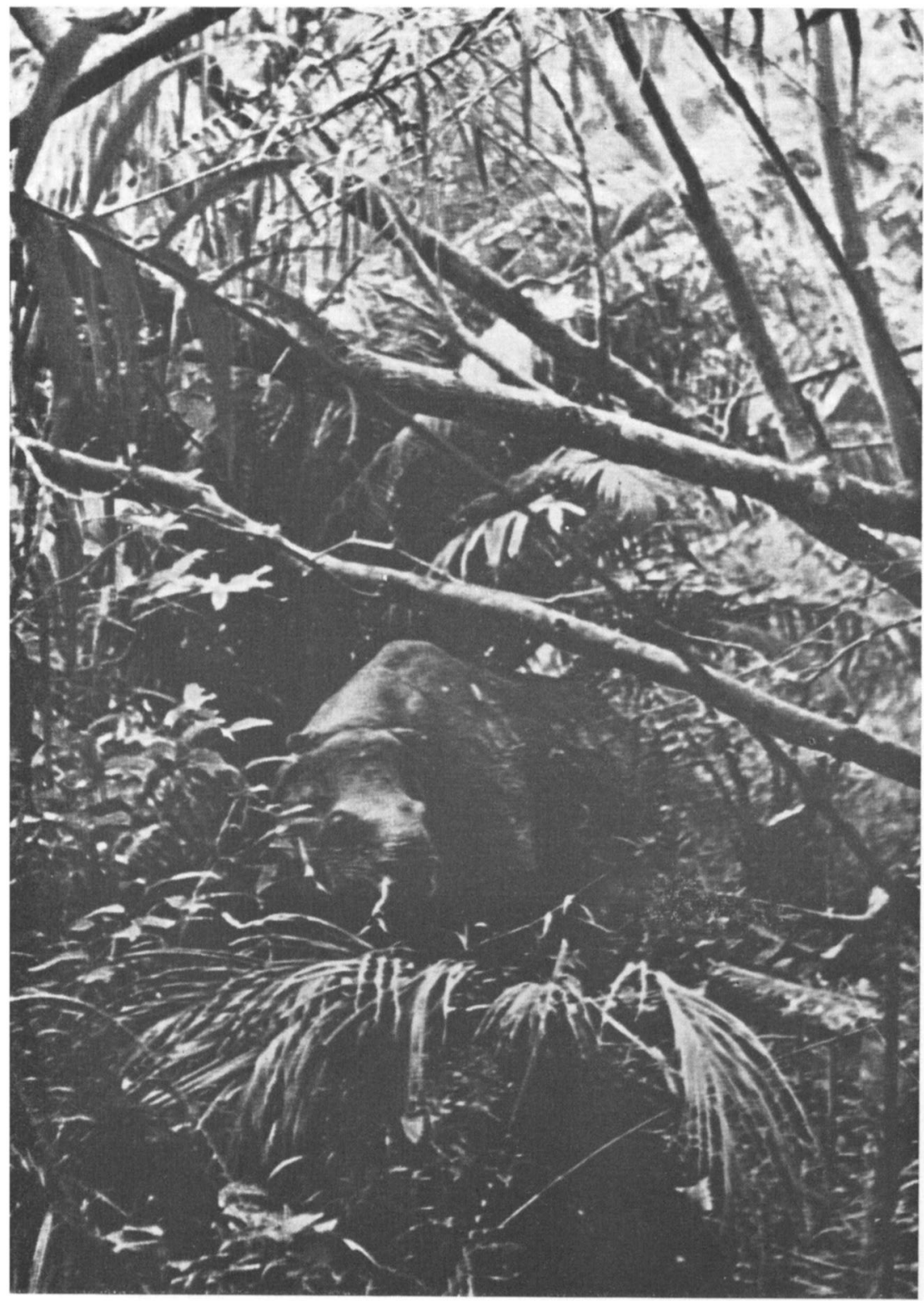

Plate 3: JAVAN RHINO. This remarkable photograph of one of the rarest, most difficult to see, and least photographed animals in the world was taken in the Udjung Kulon reserve by Helmut Barth in 1963. It is reproduced from the colour photograph in Eugen Schuhmacher's book 'The Last of the Wild', by kind permission of the publishers; see the review on page 369. 

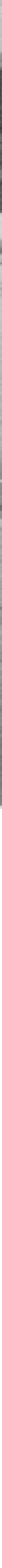

Plates 4-6: RHINO TRACES. All that most visitors to Udjung Kulon ever see of a Javan Rhino: the bent sapling, a pile of dung, footprints leading into the forest. Photographs by Dr and

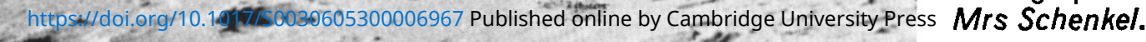




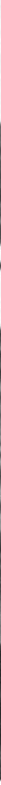

Plate 7: THE 'BADAK'. Dr Schenkel and some of the guards in Udjung Kulon going ashore from the boat Badak which was paid for by the FPS/WWF Revolving Fund.

Without a boat it is impossible even to get to the reserve. 


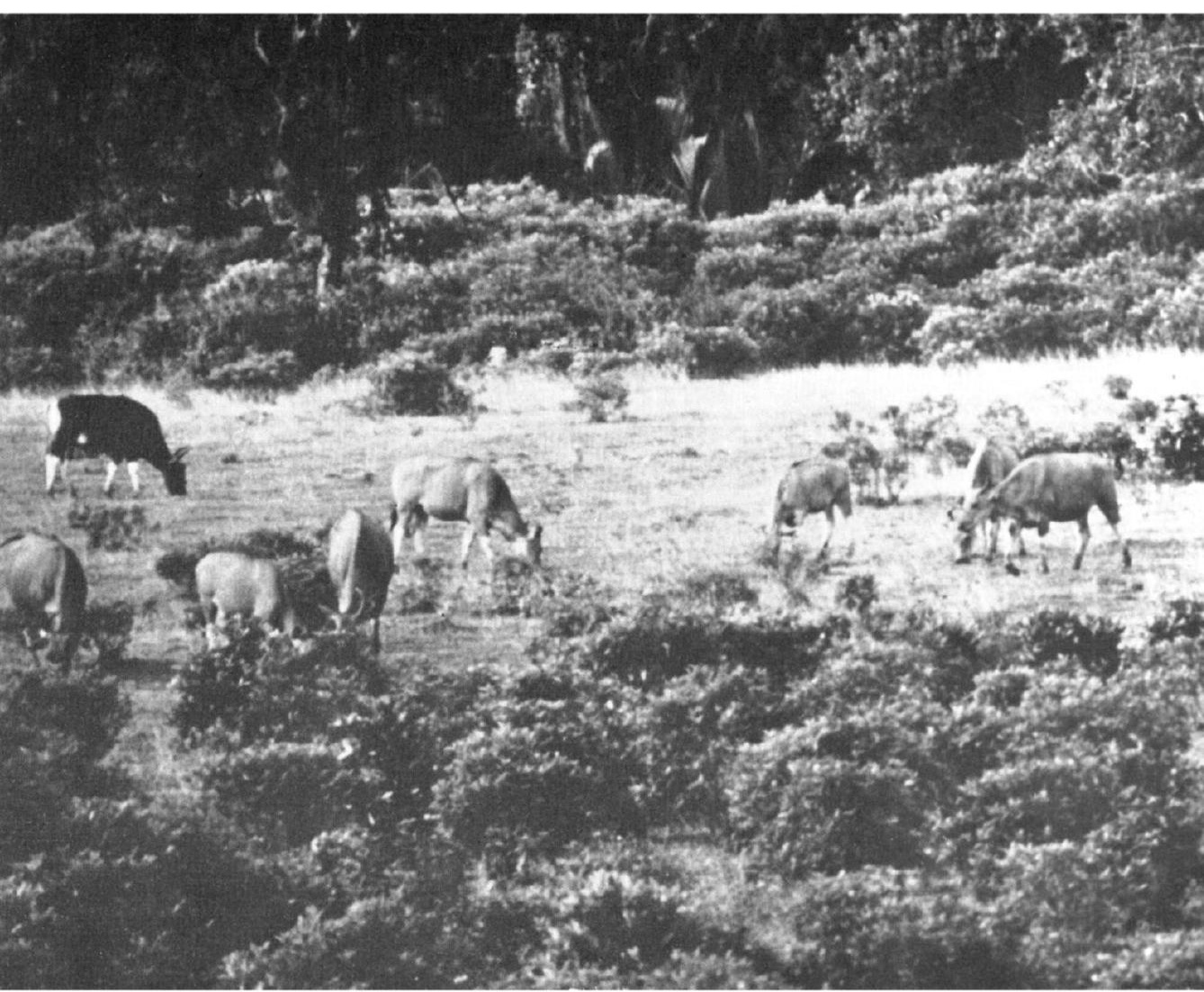

Plate 8: BANTENG in one of the grazing grounds in Udjung Kulon that are becoming overgrown. The dark animal on the left is a bull. 
food due to ecological changes in the reserve. The rhinos feed on saplings of a large number of trees, and the vegetation of Udjung Kulon is working up to a climax that is not favourable for these saplings; certain large trees, especially palms, are now shading them out. This high growth has been retarded hitherto by human settlement and cultivation, by volcanic eruptions such as the Krakatau eruption in 1883 , by the clearing of grazing grounds for ungulates and by larger populations of the rhino and banteng themselves. But in recent years grazing areas have been allowed to grow over, with a resulting decrease in banteng and deer, and the small numbers of ungulates have little effect on the vegetation. In the dry season they are forced to migrate widely for food. In $1964 \mathrm{Dr}$ Lee Talbot could describe the reserve as 'full of animals', but this is now far from the case. The only numerous large mammal is the wild pig, though some leopards and possibly even clouded leopards survive. Tigers are extinct.

\section{Complementary Role with the Banteng}

The local shortage of food forces the rhinos to make long treks every night; these are strenuous and may mean that the animals do not get enough food for the amount of effort involved, which could be a factor in their apparently low breeding rate. Another result of these long treks is that there is no system of well developed paths, and the decrease in the banteng contributes to this. Banteng and rhino have more or less complementary roles - the rhino, is a browser the banteng a grazer, so they do not compete for food. But both use and keep open the same system of tracks, and although rhino can push through thick vegetation it is an advantage for them to be able to move easily and quickly from one feeding area to another. A track system also facilitates orientation and contact with other rhinos. All these negative factors help to reduce the breeding rate, and therefore the population growth.

In consideration of these facts the Schenkels recommend that the vegetation in the reserve should be managed in the interests of all the wildlife, but particularly the rhino, with grazing grounds for ungulates kept open and methods developed to increase the growth of rhino food plants. During their stay they selected three experimental areas for selective cutting of palms, and these will be watched in the next two to four years to see the effects of the cutting and whether the reduction of shade encourages the rhino's favoured saplings. In the old patrol paths in the reserve, where palms were cut down three to five years ago, saplings are now much more numerous than in the neighbouring areas.

The task of saving the Javan rhino is still in a critical stage, but the work that has been done so far, by the Talbots, Dr Verschuren and the Schenkels, has shown how vitally important it is to have these scientific studies in order to understand what are the requirements for success. The Schenkels believe that, with an efficient guard system, and carefully applied management based on scientific findings, it should be possible to keep Udjung Kulon as a sanctuary and to save the Javan rhino from threatened extinction. 